\title{
Towards a Reconstruction of Theoretical Foundations of Enterprise Architecture Management
}

\author{
S. Weiss, S. Aier, R. Winter ${ }^{1}$
}

\begin{abstract}
Enterprise architecting has grown to a well-established discipline. Based on the design science research paradigm, a multitude of models and methods have been developed and real-world practices have been assessed. However, as the development of EAM has been rather practice-driven, a theoretical foundation for EAM seems to be lacking. Based on a set $S 1$ of well-known EAM properties and EAM means-ends relationships, this paper addresses this gap by identifying an initial set $S 2$ of information systems theories that can serve as theoretical grounding for EAM. As a first iteration of Hevner's [1] Rigor Cycle, we identified twelve theories that can be related to EAM and have the potential to serve as a theoretical grounding for more profound EAM design theories.
\end{abstract}

\section{Introduction}

Enterprise architecture (EA) describes the fundamental structures of an organization (company, government agency etc.) and supports its transformation by explicating the components as well as their interdependencies of the "business to IT stack". Enterprise architecture management (EAM) is concerned with the establishment and continuous development of EA. As such, the notion of EAM goes beyond EA modeling and includes the management tasks of planning and controlling enterprise transformation from an architectural perspective [2].

In recent years, EAM has been established in a growing number of organizations as means to ensure transparency, agility and consistency, compliance and efficiency [3]. The overall development of EAM has been primarily practice-driven, though. From a scientific perspective, a number of models and methods have been developed using a design science research (DSR) approach. A number of authors provide overviews of respective EAM approaches that have evolved based on varying understandings, origins, representations and targets of EA [4,5]. From a practice perspective, it is frequently assessed (e.g. by Gartner, Forrester) how EAM is conducted in companies, i.e. what practitioners understand under EAM; what the objectives of EA programs are; and which aspects is currently being worked on.

\footnotetext{
${ }^{1}$ University of St. Gallen, Institute of Information Management, St. Gallen, Switzerland, simon.weiss@unisg.ch, stephan.aier@unisg.ch,robert.winter@unisg.ch
} 
An aspect EAM research is lacking, though, is its theoretical foundation. To the best of the authors' knowledge, there exists no comprehensive overview of theories that can contribute to EAM so far. However, a theoretical foundation would be beneficial to rigor design science research [6,7], i.e. the enhancement of the knowledgebase of applicable EAM design knowledge. The goal of this paper therefore is to provide an overview of information systems (IS) theories that can serve as a basis for EAM research and eventually help to construct better design theories in this area.

The remainder of the paper is structured as follows: In section two we outline the conceptual foundations of our research. In section three we link identified IS theories to EAM properties and EAM means-ends relationships. The article closes with a short summary and outlook.

\section{Conceptual Foundations}

The rationale for this paper is based on Hevner's [1] rigor cycle. "The Rigor Cycle connects the design science activities with the knowledge base of scientific foundations, experience, and expertise that informs the research project" [1]. In this respect, we intend to relate known (kernel) theories (cause-effect relationships) to observable and apparently effective EAM practices (means-ends relationships), aligned to Goldkuhl's [8] conception of grounding of design theory [also 6,7]. As mentioned earlier, we can observe both prescriptive statements (design theories e.g. in the form of EAM models and methods) as well as instantiated action in EAM practice. In this paper, we approach the issue of theoretical grounding. Accordingly, (kernel) theories can provide validated cause-effect relationships that theoretically ground means-ends relationships within the domain of EAM. Being a first iteration of the rigor cycle, this paper intends to:

- Establish an initial set $S 1$ of well-known EAM properties and EAM meansends relationships, and

- Search for candidates in IS theory that can serve as theoretical grounding set $S 2$ of cause-effect relationships.

\section{Linking IS kernel theories to EAM}

As a first source of potential kernel theories of EAM, we focused on the list of IS theories from York University. ${ }^{2}$ The list is comprised of 84 theories that are used in IS research (effective June 2011). Even though on varying levels of detail, each

\footnotetext{
${ }^{2}$ Available at http://www.fsc.yorku.ca/york/istheory/wiki/index.php.
} 
summary comprises information about main construct(s)/factor(s), originating author(s), seminal articles, originating area etc.

In a reverse-search, we looked at every single theory and identified the ones that can be related to one or more elements of $S 1$. We could observe that IS theories can be related to either the mechanisms of the core components of EAM (type 1), or to the impact of EAM in its organizational context (type 2). Type 1 theories relate to how the sub-functions of EAM (e.g. EA planning, development, communication, controlling, governance) should be managed, whereas type 2 theories can be related to the way the EAM function interfaces with its environment and why EAM seems to be well-suited for dealing with certain managerial issues in a potentially organization-overarching context. Table 3.1 provides an overview of the relations between the elements of sets S1 and S2, and respective types. Below, the essence of each theory and its links to EAM are described briefly.

Table 3.1: S1-S2 allocation matrix incl. theory types (T1 or T2)

\begin{tabular}{|c|c|c|c|c|c|}
\hline & \multicolumn{5}{|c|}{ Set $S 1$} \\
\hline & $\begin{array}{l}\text { Transparency } \\
\text { by modeling }\end{array}$ & $\begin{array}{l}\text { Coordination } \\
\text { by planning }\end{array}$ & $\begin{array}{l}\text { Consistency } \\
\text { by principles }\end{array}$ & $\begin{array}{l}\text { Effectiveness } \\
\text { by consulting }\end{array}$ & $\begin{array}{l}\text { Compliance } \\
\text { by reviews }\end{array}$ \\
\hline T1 (GST) & $\mathrm{T} 1$ & & & & \\
\hline T2 (Agency) & & $\mathrm{T} 2$ & & & \\
\hline T3 (DOI) & $\mathrm{T} 2$ & & & $\mathrm{~T} 2$ & \\
\hline T4 (Dyn. Cap.) & & $\mathrm{T} 2$ & & $\mathrm{~T} 2$ & \\
\hline T5 (OIPT) & $\mathrm{T} 2$ & & $\mathrm{~T} 2$ & $\mathrm{~T} 2$ & \\
\hline ઈે T6 (Admin. Beh.) & $\mathrm{T} 1$ & & & & \\
\hline$\stackrel{\Perp}{\curvearrowleft}$ T7 (Contingency) & $\mathrm{T} 1$ & $\mathrm{~T} 1$ & $\mathrm{~T} 1$ & & \\
\hline T8 (Inst. Theory) & & & & $\mathrm{T} 1 / \mathrm{T} 2$ & $\mathrm{~T} 1 / \mathrm{T} 2$ \\
\hline T9 (ANT) & $\mathrm{T} 1$ & $\mathrm{~T} 2$ & & $\mathrm{~T} 2$ & \\
\hline T10 (Cogn. Load) & $\mathrm{T} 1$ & & & & \\
\hline T11 (SSM) & & & $\mathrm{T} 2$ & $\mathrm{~T} 2$ & \\
\hline T12 (SNT) & $\mathrm{T} 2$ & $\mathrm{~T} 2$ & & & \\
\hline
\end{tabular}

Theory 1-General Systems Theory (GST): Today, a lot of variations of this general theory exist, while the common thought being that any entity (e.g. an organization) consists of parts and relations between these parts, which connect them into a whole. Rather than regarding an entity's or organization's parts separately, systems theory focuses on the arrangement of and relations between the parts [9].

This thought is also inherent in EAM, which regards enterprises as systems with numerous parts such as strategies, products, processes, organizational units, (IT) systems, etc., which are all related to each other in a certain way, but can be structured into (logical) subsystems, e.g. different layers of abstraction, for the purposes of complexity-reduction, decoupling and containment [10,11]. One can 
therefore state that, on a very basic level, systems theory supports EAM with its approach to focus on understanding the relations between an organization's components, in particular between business and IT [12].

Theory 2-Agency Theory: Agency theory, or principal-agent problem, deals with the difficulties that arise when a principal hires an agent in the light of incomplete and asymmetric information and self-interests of both parties [13].

In our setting, this problem may for instance occur (and as a matter of fact, we regularly experience this with our industry partners), when a project manager is reluctant to spent $\$ 10 \mathrm{M}$ more, even if it would save another unit $\$ 20 \mathrm{M}$ and the directive of the top manager was to maximize benefit for the whole organization. Only an overarching program management or EA approach is able to detect, verify, and resolve such issues. Agency theory is therefore in favor of EAM as an overarching planning tool facilitating a mitigation of principal-agent problems.

Theory 3-Diffusion of Innovations Theory (DOI): Diffusion of innovations theory (also known as innovation diffusion theory (IDT)) is widely used in IS. The theory aims at explaining how, why, and at what rate innovations, in particular new technologies, are adopted by societies or organizations. While many different variations of DOI are in existence, the three most important antecedents to the adoption of innovations and IS implementation success have been identified to be technical compatibility, technical complexity (ease of use) and relative advantage (perceived need) [14].

The link to EAM is that EAM particularly helps coping with the former two aspects. As EA intends for instance to provide transparency across architectural layers and to unveil links of IT to upper layers, it makes the possible impact of innovations transparent. EAM can therefore be regarded a suitable means-ends relationship for implementation success or technology adoption.

Theory 4-Dynamic Capabilities: Teece et al. [15] define dynamic capabilities as "the firm's ability to integrate, build, and reconfigure internal and external competences to address rapidly changing environments." Dynamic capabilities theory states that sustainable competitive advantage depends upon such capabilities of resource development and renewal.

As EAM clearly deals with methods for tackling the tasks mentioned in the definition, it represents in itself a dynamic capability. Thus, it provides a means for the end of competitive advantage.

Theory 5-Organizational Information Processing Theory (OIPT): Similar to other theories, OIPT argues that organizations require quality information for coping with uncertainty, improve decision making, and realize change. According to OIPT a fit of information processing needs and information processing capability determines the information processing performance. One of the two common strategies to cope with these challenges is to "implement structural mechanisms and information processing capability to enhance the information flow and thereby reduce uncertainty." [cf. 16,17]. 
EAM can provide means to this end by especially satisfying information needs and processing capabilities by grasping relations between organizational elements.

Theory 6-Theory of Administrative Behavior: The theory of administrative behavior holds two key concepts, namely the concept of bounded rationality and the concept of satisficing. Both concepts call for a method that capture information and complex relations in an aggregated and processable way in order to overcome the "limits in formulating and solving complex problems and in processing (receiving, storing, retrieving, transmitting) information.” [18]

To our mind, a broad (business to IT) and flat (focusing on aggregated components and relations) EAM approach is suitable for this task as opposed to approaches that focus on certain tasks in depth (e.g. business process management or IT support) [cf. 2,3].

Theory 7-Contingency Theory: Contingency theory is a class of behavioral theory that claims that there is no (single) best way to organize or lead a corporation and make decisions. Rather, the optimal approach depends upon various internal and external contingency factors [cf. e.g. 19].

We can observe many of the ideas of contingency theory to be valid for EAM as well $[2,20]$. First, a one-size-fits-all EAM approach is not reasonable. Second, EAM should fit to its wider organizational (and inter-organizational) context. After all, every organization is different and has differing EAM requirements accordingly. Third, the various EAM tasks themselves should fit, i.e. the subsystems of the EAM function (like EA planning, modeling, etc) should be aligned.

Theory 8-Institutional Theory: Institutional theory elaborates on how elements like (social or organizational) structures, rules, norms and routines are created, diffused, adopted and adapted over space and time, including potential disuse and conflict [21]. Applied to EAM, we can analogously observe that EA needs adaptation and adoption processes, and cannot be introduced in a glimpse [22]. The introduction of a (more or less powerful) EA board for instance, is regularly subject to discussions and conflicts-not to mention an enforcement of architectural transformations or universal principles.

Theory 9-Actor Network Theory (ANT): ANT claims that an actor-network resembles a heterogeneous network, which comprises not only people, but also objects and organizations, which are all together regarded as being equally important and inseparable. A significant break-down of the order of the (social) network may result when removing any actor (e.g. the president, telephones) [23].

This theory can be related to EAM from two major perspectives. From an inside-out perspective, ANT supports EAM as holistic approach to respect not only application system or processes, but resources and capabilities across all layers from strategy to infrastructure. From an outside-in, i.e. stakeholder-oriented perspective, one can infer that many (internal and external) stakeholders are important for an organization and should be catered for through respective viewpoints of the EA [24]. Disrespecting the interests of a governmental body for instance, may have tremendous consequences. 
Theory 10-Cognitive Load Theory: The theory states that the performance of learning or problem-solving is determined by cognitive load, which in turn depends upon a task-based dimension (mental load) and a learner-based dimension (mental effort). Mental load is determined by the elements of intrinsic cognitive load, extraneous load and germane load. The ease with which information may be processed in the limited working memory can particularly be affected by altering the characteristics of extraneous load and germane load [25].

EAM too intends to reduce the difficulty of tasks like business/IT alignment by providing means and methods (e.g. EA modeling) to reduce extraneous load (irrelevant details) and to increase germane load (by putting architectural artifacts into known schemas/models). A similar argumentation applies to cognitive fit theory [26], which is closely related to cognitive load theory and is consequently not explicitly treated here.

Theory 11-Soft Systems Methodology (SSM): SSM distinguishes hard and soft problems that have each its unique characteristics. As opposed to hard problems, soft problems, which are also referred to as ill-defined or wicked problems, contain social and political or generally new elements that complicate problem definition and resolution [27].

Based on SSM, EA transformation projects can clearly be regarded as soft problems due to a multitude of interdependencies that also contain social and political elements. Checkland's iterative SSM approach to address soft problems is also very close to EA development processes as they occur in EA frameworks (e.g. TOGAF). SSM may therefore contribute on how to design EAM processes.

Theory 12-Social Network Theory (SNT): In contrast to other sociological studies, SNT does not primarily assess actors' attributes, but their relationships and ties [28]. With respect to EA, a network perspective using research from social network analysis can provide a useful abstraction for understanding architecture, which can be viewed "as a network of software components linked by their interdependencies" [29]. Another research question related to SNT could be which role(s) and links certain persons responsible for EA should have in the (social) network of an organization.

\section{Discussion \& Summary}

Motivated by a lack of theoretical foundations for EAM design science research, this paper depicted an initial set $S 2$ comprised of twelve theories that can be related to the discipline of EA, used as substantiation for doing EAM, and in particular guide further research and eventually practices in the field. The discussed theories were identified based on a set $S 1$ of observed and apparently effective EAM means-ends relationships. While a more in-depth discussion of each theory is out of scope of this paper, the argumentation gives examples of how the mentioned theories can be related to EAM. The important contribution of the paper at hand is 
an initiation to discuss and rethink EAM approaches based on commonly accepted and relevant kernel theories, and to adapt or refine these theories if appropriate.

With respect to the limitations of this work, it should be noted that both sets $S 1$ and $S 2$ were developed as a first iteration of Hevner's DSR Rigor Cycle and are thus not complete. It is planned to refine and extend both sets in further iterations and to develop more profound relationships between respective elements. To this end, two issues are of particular interest: Firstly, some theories will certainly offer a better grounding and/or explanatory power for EAM than others and should therefore be prioritized for further in-depth elaboration. These theories have to be identified. Secondly, it has to be argued and assessed whether the kernel theories are applicable/adaptable the way they are, or whether mid-range theories should be constructed in order to bridge the gap between kernel theories and design theories, as proposed by Kuechler and Vaishnavi [30].

\section{References}

1. Hevner AR (2007) A Three Cycle View of Design Science Research. Scandinavian Journal of Information Systems 19 (2):87-92

2. Aier S, Gleichauf B, Winter R Understanding Enterprise Architecture Management Design An Empirical Analysis. In: Bernstein A, Schwabe G (eds) The 10th International Conference on Wirtschaftsinformatik WI 2.011, Zurich, 2011. pp 645-654

3. Winter R, Fischer R (2007) Essential Layers, Artifacts, and Dependencies of Enterprise Architecture. Journal Of Enterprise Architecture 3 (2):7-18

4. Schönherr M Towards a Common Terminology in the Discipline of Enterprise Architecture. In: Feuerlicht G, Lamersdorf W (eds) 3rd Workshop on Trends in Enterprise Architecture Research at ICSOC 2008, Sydney, 2009. Springer, pp 400-413

5. Mykhashchuk M, Buckl S, Dierl T, Schweda C Charting the Landscape of Enterprise Architecture Management. In: Bernstein A, Schwabe G (eds) The 10th International Conference on Wirtschaftsinformatik WI 2.011, Zurich, 2011. pp 570-577

6. Walls JG, Widmeyer GR, El Sawy OA (1992) Building an Information System Design Theory for Vigilant EIS. Information Systems Research 3 (1):36-59

7. Gregor S, Jones D (2007) The Anatomy of a Design Theory. Journal Of The Association For Information Systems 8 (5):312-335

8. Goldkuhl G (2004) Design Theories in Information Systems - A Need for Multi-Grounding. Journal of Information Technology Theory and Application 6 (2):59-72

9. Kast FE, Rosenzweig JE (1972) General Systems Theory: Applications for Organization and Management. Academy Of Management Journal 15 (4):447-465

10. Mesarovic MD, Macko DS, Takahara Y (1970) Theory of Hierarchical, Multilevel Systems, vol 68. Mathematics in Science and Engineering. Academic Press, New York

11. Aier S, Winter R (2009) Virtual Decoupling for IT/Business Alignment - Conceptual Foundations, Architecture Design and Implementation Example. Business \& Information Systems Engineering 1 (2): $150-163$

12. Kloeckner S, Birkmeier D (2010) Something Is Missing: Enterprise Architecture from a Systems Theory Perspective. In: Dan A, Gittler F, Toumani F (eds) Service-Oriented Computing. ICSOC/ServiceWave 2009 Workshops. Springer, Berlin, pp 22-34

13. Eisenhardt KM (1989) Agency Theory: An Assessment and Review. The Academy of Management Review 14 (1):57-74

14. Rogers EM (2003) Diffusion of Innovations. 5 edn. Free Press, New York 
15. Teece DJ, Pisano G, Shuen A (1997) Dynamic Capabilities and Strategic Management. Strategic Management Journal 18 (7):509-533

16. Galbraith JR (1973) Designing Complex Organizations. Addison-Wesley, Boston, MA

17. Premkumar G, Ramamurthy K, Saunders CS (2005) Information Processing View of Organizations: An Exploratory Examination of Fit in the Context of Interorganizational Relationships. Journal Of Management Information Systems 22 (1):257-294

18. Williamson OE (1981) The Economics of Organization - The Transaction Cost Approach The American Journal of Sociology 87 (3):548-577

19. Weill P, Olson MH (1989) An Assessment of the Contingency Theory of Management Information Systems. Journal Of Management Information Systems 6 (1):59-85

20. Leppänen M, Valtonen K, Pulkkinen M Towards a Contingency Framework for Engineering an Enterprise Architecture Planning Method. In: The 30th Information Systems Research Seminar in Scandinavia (IRIS 2007), Tampere, Finland, 2007.

21. Scott WR (1987) The Adolescence of Institutional Theory. Administrative Science Quarterly $32(4): 493-511$

22. Ross JW (2003) Creating a strategic IT architecture competency: Learning in stages. MIS Quarterly Executive 2 (1):31-43

23. Law J (1992) Notes on the theory of the actor-network: Ordering, strategy, and heterogeneity. Systemic Practice and Action Research 5 (4):379-393

24. Kurpjuweit S, Winter R Viewpoint-based Meta Model Engineering. In: Reichert M, Strecker S, Turowski K (eds) 2nd International Workshop on Enterprise Modelling and Information Systems Architectures, St. Goar/Rhine, Germany, 2007. Gesellschaft für Informatik Köllen, pp 143-161

25. Sweller J (1988) Cognitive load during problem solving: Effects on learning. Cognitive Science 12 (2):257-285

26. Vessey I (1991) Cognitive Fit: A Theory-Based Analysis of the Graphs Versus Tables Literature. Decision Sciences 22 (2):219-240

27. Checkland P (2000) Soft Systems Methodology: A Thirty Year Retroperspecitve. Systems Research and Behavioural Science 17 (1):11-58

28. Wasserman S, Faust K (1994) Social Network Analysis: Methods and Applications. Cambridge Univ. Press, Cambridge

29. Dreyfus D, Iyer B Enterprise Architecture: A Social Network Perspective. In: Sprague RH, Jr. (ed) 39th Annual Hawaii International Conference on System Sciences (HICSS'06), Hawaii, 2006. IEEE Computer Society Press, pp 178a-178a

30. Kuechler B, Vaishnavi VK (2008) On theory development in design science research: anatomy of a research project. European Journal Of Information Systems 17 (5):489-504 